\title{
O dilema do prisioneiro e a ética
}

ISAAC EPSTEIN

\author{
"Mas se houver dano grave então darás vida por vida, \\ olho por olho, dente por dente, \\ mão por mão, pé por pé ..." \\ Exodo, 21, 23-24 \\ "Vós tendes ouvido o que se disse: \\ olho por olho, dente por dente. \\ Eu porém digo-vos que não resistais ao que vos fizer mal: \\ mas se alguém te ferir, na tua face direita, \\ oferece-lhe também a esquerda ..." \\ Evangelho de S. Mateus, 5, 38-39 \\ "Age apenas segundo uma máxima tal que possas \\ ao mesmo tempo querer que ela se torne lei universal ..." \\ Kant, em Imperativo Categórico \\ "Quero levar vantagem em tudo ..." \\ Lei de Gerson
}

ÉTICA TEM SIDO, em geral, definida como a ciência da conduta. Como
tal, foi objeto de normas religiosas reveladas, especulações filosóficas
baseadas geralmente na razão prática, descrição empírica de costumes de uma comunidade feita por cientistas sociais etc.

Os filosofos gregos costumavam subordinar a ética à busca de uma vida feliz, seja a custa de uma moderação das paixões (epicuristas), seja na sua completa superação (estóicos), ou no seu domínio pela razão através da ação (Aristóteles).

A filosofia ética da ilustração foi, sobretudo, a recuperação do eudemonismo dos antigos, dentro de uma ótica individualista. As filosofias derivadas do positivismo, por sua vez, negam a validade dos imperativos da razão prática $\mathrm{e}$ consideram válidas apenas as proposições empiricamente verificáveis. Como as proposiçốes normativas da ética não são nem tautológicas, nem factuais, elas se tornam não-significativas (Rouanet, 1992: 154).

Como então achar fundamento para a ética, notadamente num mundo chamado de pós-moderno que recusa todas as metas-narrativas? 
Em verdade, a prática real da luta pelo poder, nas suas várias formas, obedece a normas mais retaliatórias do que as máximas religiosas ou filosóficas como as mencionadas na epígrafe. O desligamento da arte da política da moral tradicional é feito por Maquiavel. Seus conselhos ao Príncipe (como por exemplo: "....as violências devem ser feitas todas ao mesmo tempo, a fim de que seu sabor, persistindo menos tempo, ofenda menos...") revelam um objetivo primordial: a governabilidade do estado. "Arranque os dentes e os olhos para tornar o inimigo inofensivo" é uma norma seguida por muitos, compreendida por todos, mas que não está inscrita no catecismo de qualquer religião.

Será então a lei de Gerson, a proposta de uma ética agonística, na qual a competição é um valor e a vitória a qualquer custo, um fim?

Por outro lado, os comportamentos cooperativos e parcialmente altruístas, no sentido de conterem um desapego inicial em maximizar imediatamente as próprias vantagens, nos leva a uma indagaçáo do próprio comparecimento deste termo nos discursos sobre o comportamento humano.

Historicamente, o termo altruismo tem ocorrido mais freqüentemente nos textos religiosos ou literários do que nos discursos das ciências humanas. Nas últimas décadas, no entanto, o altruísmo tem tido duas entradas no campo das ciências do comportamento. A primeira se refere a estudos de etologia e comportamento animal. A segunda, ao próprio comportamento humano quando descrito pela teoria de jogos, especificamente na modalidade denominada de dilema do prisioneiro.

Quanto ao comportamento animal, o desempenho altruista, apesar de contrário ao que seria de se esperar pela teoria darwiniana da evolução biológica (1), tem sido verificado em várias circunstâncias.

Alguns autores, etólogos renomados, apontam para analogias entre esses desempenhos nos animais e nos homens. (2) A preocupação teórica dos pesquisadores desse tipo de comportamento tem sido a de conciliar o altruismo animal com o princípio da sobrevivência do mais apto, pedra angular, da teoria da evolução das espécies (3).

A teoria dos jogos, por sua vez, construída para dar conta primordialmente do comportamento dos agentes econômicos extravasou os limites iniciais propostos por seus autores (Von Neumann \& Morgenstern, 1967). O que nos pode ilustrar a ciência feita sob esta rubrica acerca dos comportamentos e das normas éticas? Como fica a técnica da ação, a razão instrumental a serviço da agonística dos combates econômicos ou mesmo militares, cujo objetivo é maximizar os próprios benefícios, à luz dos preceitos éticos tradicionais das religiôes e dos 
imperativos categóricos? Será inevitável que não exista possibilidade alguma de fundamentar objetivamente a escolha moral?

Não será, ao revés, possível fundamentar o comportamento altruísta a partir de proposições empiricamente verificáveis como imanentemente pragmáticas? Em outras palavras, uma colaboração da ciência racional e empírica para a justificação de certas normas éticas?

Essa possibilidade significaria, por exemplo, verificar empiricamente quais dos preceitos éticos e religiosos ou filosóficos teriam maior valor de sobrevivência quando em face de comportamentos mais egoístas ou predatórios.

Que o Homo Economicus (4) seja menos falcão e mais pomba e mesmo assim consiga sobreviver aos seus semelhantes, apenas falcōes?

Que tirar vantagem máxima aqui e agora e sempre possa não ser a melhor estratégia, mesmo num universo governado soberanamente pela mão invisivel de Adam Smith?

Esta a contribuição de um setor limitado da teoria de jogos conhecido como o dilema do prisioneiro pode dar a questão ética.

Resta, evidentemente, resguardar o fato de que a justificativa do comportamento ético, ou pelo menos não totalmente egoísta no sentido imediato, tem como tela de referência um valor positivo para a sobrevivência de seus praticantes. Um efeito pragmático explícito, sem o qual não seria possível utilizar-se a razão instrumental na descrição de alguns comportamentos como meios que, em determinadas circunstâncias, são mais ou menos eficazes para garantir a sobrevivência não só dos indivíduos, mas também de grupos ou constelaçóes de indivíduos.

De qualquer modo, no mínimo, esta contribuição pode subsidiar o apoio empírico a algumas prescriçóes reservadas ao domínio dos mandamentos religiosos ou dos imperativos da razão prática.

Que não cause estranheza, portanto, a incursão da etologia animal e das teorias agonísticas mais apropriadas às guerras e aos empedernidos combates econômicos nos domínios mais ou menos sacralizados dos mandamentos religiosos e dos imperativos categóricos. No mínimo isto pode mostrar que estas prescrições a priori não necessitam ser totalmente arbitrárias.

O dilema do prisioneiro é um jogo de soma diferente de zero que ilustra tanto a falha do princípio Minimax quanto a do princípio da estratégia dominan- 
te (5). Neste jogo frustrante, se os dois jogadores escolhem suas estratégias ótimas cada um deles ganha menos do que se ambos tivessem escolhido uma estratégia não-ótima.

Estratégia ótima significa a maximização da utilidade por parte de cada participante. Nos jogos de soma zero, essa maximização é inequívoca. Nas coalizões onde a soma é diferente de zero, ocorre um espaço de manobra no qual há uma procura de otimização entre os benefícios de cada um dos participantes (parcialmente em conflito) e aquela parcela que deve ser partilhada entre eles e, correspondente ao quinhão do jogo diferente de zero.

Mas as coalizóes pressupóem a comunicação entre os jogadores. Quando esta é impossível, a estrutura do jogo denominado dilema do prisioneiro conduz a um paradoxo, pois a racionalidade egoista, quando exercida por cada um dos participantes, conduz a um desastre para ambos.

A estrutura do dilema do prisioneiro torna muito difícil a busca da melhor estratégia para ambos os participantes. Apenas a comunicação entre eles poderia operacionalizar este caminho, no qual ambos devem executar o seu lance simultaneamente. A restrição à comunicação pode obstruir definitivamiente esta solução, melhor para ambos.

A expressão dilema do prisioneiro deriva de uma estória que era utilizada para ilustrá-la: Dois cúmplices são interrogados separadamente pela polícia. Apesar de serem considerados culpados de um crime grave (digamos, um latrocínio), a polícia não possui provas suficientes para indiciar qualquer dos dois. Têm, porém, provas para indiciá-los por um crime menor (porte de armas). As alternativas à disposição dos suspeitos A e B são: confessar [estratégia (1)], ou não confessar o crime mais grave [estratégia (2)]. Separados, não podem comunicarse. Os resultados de tal estratégia são os seguintes: se ambos confessarem (1), terão sentenças pesadas, mas redutíveis devido a confissão, às quais atribuiremos o valor (-5); se um deles confessar, testemunhando contra o cúmplice, este terá sua pena agravada $(-10)$ e o informante será libertado $(+10)$. Se nenhum confessar, ambos só poderão ser condenados pelo crime menor $(-2)$, valores estes obviamente arbitrários, e cuja significação é apenas relativa, de uns aos outros.

A matriz deste jogo poderá ser representada pelo quadro apresentado a seguir, se atribuirmos os valores de $(-2)$ para cada prisioneiro, pelo resultado correspondente à não-confissão de ambos. $\mathrm{O}$ valor $(+10)$ corresponderá à absolvição do traidor e o valor de (-10) à pena agravada, do cúmplice traído.

Nesta matriz, o primeiro número de cada quadro representa o resultado para o jogador A e o segundo, o resultado para o jogador $B$. 


\section{B1 (confessa) B2 (não confessa)}
Al (confessa)
$(-5)(-5)$
$(+10)(-10)$
A2 (não confessa)
$(-10)(+10)$
$(-2)(-2)$

Qual a conduta racional dos cúmplices? A pode pensar: "Se eu confessar, o pior que me pode acontecer é a pena de $(-5)$, e o melhor a de $(+10)$. Se não confessar, o pior é (-10) e o melhor (-2)." Como a situação de B é simétrica, ele pensará de modo idêntico e, como resultado destas estratégias max-min, ambos confessarão, com o resultado de (-5) para cada um.

Se pudessem se comunicar poderiam combinar entre si de modo a ninguém confessar, com o resultado de (-2) para cada um, o que melhoraria a posição de ambos em relaçáo ao resultado anterior.

As estratégias dos jogos de soma zero são formuladas tendo em conta o interesse exclusivo de cada parte. A partir desta racionalidade, que também é atribuída a ambos os adversários, impóe-se a estratégia do max-min. Mas este cálculo, adequado nos jogos de soma zero, pode levar a um resultado que não é o melhor em certos jogos de soma diferente de zero, como os do tipo do dilema do prisioneiro.

No caso dos jogos de soma zero, a escolha de uma estratégia dominante, se esta existir, é a única escolha racional. Este, porém, náo é o caso do dilema do prisioneiro. Aqui, se ambos escolherem as suas estratégias dominantes, ambos terão um resultado pior do que se escolhessem as estratégias dominadas.

Uma das saídas desta situação seria um acordo prévio entre os participantes. Mas, se a situação, o contexto, ou mesmo as regras do jogo tornam inviável ou próbem a comunicação? Ou, pior ainda, se as partes não confiam mutuamente no cumprimento do acordo prévio, quanto mais não seja, pela ausência de uma instância capaz de garanti-lo?

Rapoport (1969:48-57), em plena guerra fria, assume uma matriz semelhante para a alternativa de desarmamento, (Estratégia $X$ ) ou armamento crescente (Estratégia $Y$ ) das duas grandes potências que se enfrentavam.

A estratégia $\mathrm{Y}$ é ditada pelo interesse de apenas uma das partes e, a X pelo interesse comum. Esta última demanda um fator novo, que não existe nos jogos de soma zero: a confiança mútua. Com a escolha da estratégia $\mathrm{X}$, o jogador não controla mais sozinho o resultado da partida. Haverá uma possibilidade de se racionalizar a escolha cooperativa? Em outras palavras, é possível racionalizar a confiança mútua? 
Confiar no outro participante significa supor que ele não escolherá a estratégia dominante e isto é o mesmo que lhe negar a racionalidade da estratégia Min-Max. De outro lado, ser digno de confianfa significa descartar a estratégia dominante em favor da dominada, o que, por seu lado, não é um desempenho racional à luz da teoria de jogos.

Se foi possível escrever este artigo é porque, pelo menos até o momento, tem prevalecido o bom-senso para frear a corrida armamentista. Como resolver este dilema em nível de casos mais paroquiais de competição e cooperação, ou mesmo aqueles que envolvam problemas coletivos mais gerais?

Uma das maneiras de se superar o impasse é esticar o dilema do prisioneiro para duas partidas sucessivas. Neste caso, um exame mostra que a superioridade racional da estratégia (1) não subsiste. Esta nova situação corresponde a um superjogo, no qual as duas partidas sucessivas se transformam em lances.

No caso do jogo em dois lances, a estratégia hostil não é mais obviamente superior a qualquer oponente, amistoso ou hostil, como era no jogo de um único lance (6). Mas a extensão teórica do exame do dilema do prisioneiro pressupóe uniformidade dos participantes quanto a sua inteligência e demais fatores da personalidade de cada um. Trata-se então de uma população homogênea em todos os atributos, exceto aqueles especialmente discriminados na descrição do jogo. As soluçóes teóricas aplicáveis a jogadores impessoais provêm, em conseqüência, de quadros de referência para a medida do comportamento de jogadores diferenciados.

Um campo de pesquisa tem se desenvolvido a partir de torneios experimentais versando sobre o dilema do prisioneiro. Diferenças de comportamento entre diferentes tipos de jogadores têm sido examinadas. Experimentos têm focalizado o efeito de diferentes etnias, nas estratégias; o modo real pelo qual prisioneiros reais jogam este dilema; os experimentos com estudantes do secundário, com crianças, com crianças comparadas com adultos; os efeitos da diferença de sexo, e até o desempenho no dilema do prisioneiro, como medida de confiança entre paciente esquizofrênicos.

Duas das mais importantes variáveis de controle no estudo dos jogos de duas pessoas cuja soma difere de zero são o nível de comunicação e as interaçóes pessoais entre os jogadores: se são conhecidos entre si, se podem se ver mutuamente, conversar etc.

Nas últimas décadas foram realizados milhares de experimentos envolvendo jogos interativos com dois participantes e soma diferente de zero, particularmente experimentos com jogos de estrutura semelhante ao dilema do prisioneiro. 
Nestes torneios de laboratório, os traços de personalidade dos atores, sua capacidade de memória, habilidade de processar dados e matizes no controle do experimento são fatores que intervêm nos resultados.

Um dos primeiros torneios foi o proposto por Axelrod (1984), no qual numerosos pesquisadores e especialistas da teoria dos jogos submeteram suas propostas de estratégias a serem assumidas pelos participantes. As estratégias foram entáo comparadas entre si e a que forneceu o melhor resultado foi a do "Toma cá, dá lâ" (Tit for Tat), cujo o primeiro lance era sempre cooperativo.

No dilema do prisioneiro simples, quando é realizada apenas uma partida e não são previstas outras partidas, a cooperaçáo inicial de um participante arriscase a fracassar contra um oponente que obedece a lei de Gerson. Para evitar tal fato deve partir traindo, pois no mínimo ganha algo (se o adversário fizer o mesmo) $\mathrm{e}$ até muito mais se $\mathrm{o}$ adversário for do tipo bonzinho, que coopera sempre.

Esta situação única é rara na vida real. É mais provável que o jogo continue com as mesma pessoas, isto é, que uma partida do dilema se transforme num lance de uma partida mais longa. Nesta possibilidade, de jogos repetidos não há uma estratégia ótima para todos os casos. $O$ jogo se torna contingente na medida que o resultado dependerá do tipo de parceiro e do contexto. Se o jogador encontra um traidor empedernido, ele também deve trair. Se, por outro lado, encontra um cooperador incansável, não importa quantas vezes é traído (Se alguém bater, oferece a outra face). Se quiser maximizar seus benefícios, deve ainda trair.

Se, porém, enfrentar um participante que coopere até que o seu oponente traia, e daí em diante nunca mais cooperar, deve cooperar. Mas mesmo que o Tit for Tat tenha sucesso em várias situações, ele pode ser derrotado por uma estratégia Tit for two Tats. Esta estratégia mais generosa indica a retaliação somente após duas traiçóes do oponente. Esta característica generosa de perdoar uma, e apenas uma, retaliação e só retaliar após facilitava a cooperação dos jogadores a longo prazo e, mesmo que o Tit for two Tats não pudesse vencer num único encontro, fazia mais pontos ao longo do torneio.

Axelrod realizou um segundo torneio em 1979. Tit for two Tats foi um dos 63 programas que participaram. Assim, não obstante ter vencido o torneio anterior, ficou em $24^{\circ}$ lugar quando ocorreu a programação de estratégias mais duras para tirar vantagem da generosa Tit for two Tats. Elas foram programadas para saber se o Tit for two Tats só retaliaria após duas defecçóes após o que traiam alternadamente. Assim conseguiram faturar muitos pontos, uma vez que o Tit for two Tats não estava programado nem para retaliar e nem conseguia levar os outros à cooperação. Nesse torneio o vencedor foi novamente o Tit for Tat, pois mostrou poder reagir contra oponentes egoístas. Se o oponente trai, assim o faz Tit for Tat. 
O jogador egoísta não vai longe e Tit for Tat acumula pontos quando joga com cooperadores.

Em 1980 Axelrod (1984) realizou um novo tipo de competição. Utilizou então programas de computadores para simular uma seleção natural entre os vários desempenhos. Os participantes formavam uma população ecológica que se alterava após a repetição do jogo. Assim, as estratégias que ganhavam mais pontos durante a primeira rodada, por exemplo, seriam recompensadas com descendência. Duas ou mais versóes de si mesmas participariam da nova rodada. Deste modo, pode constituir populaçóes de cooperadores e traidores. Durante as rodadas que se sucederam, as estratégias bem-sucedidas multiplicavam-se, enquanto que as menos bem-sucedidas desapareciam.

Observamos aqui a influência da racionalidade do modelo da evolução biológica como paradigma conduzindo o atributo sobrevivência enquanto vetor da implantação dos desempenhos de cooperação.

Uma das características do Tit for Tat é a de perder a primeira partida quando em meio de traidores. Mas no meio de cooperadores, o Tit for Tat se dá melhor do que os traidores, que apenas faturam o mínimo quando interagem entre si. Os "Tit for Tat" têm resultados melhores quando agem em grupos. Os traidores, mesmo quando em proporção pequena no meio dos cooperadores, logo assumem o controle.

Mas o programa de Tit for Tat tinha uma imperfeição: era perfeito demais, não tinha tolerância para erros. Enquanto os programas para computador não exibem falhas, os animais e os seres humanos erram. Alguém vê um amigo, e não o reconhecendo, o agride. O programa do Tit for Tat pode cair num ciclo infindável de retaliações. Como deve sempre ferir os traidores, um sinal mal interpretado, 0 desvia da cooperação.

O pesquisador Sigmund Karl (Bass, 1993) introduziu um programa com uma porcentagem de perdôes no Tit for Tat o que, em palavras, significa: "Sempre retorne a cooperação com cooperação, e quando enfrentar a retaliação coopere em média, porém aleatoriamente, uma vez em cada três”. O programa foi denominado Tit for Tat Generoso.

Um torneio organizado por este pesquisador em 1991 utilizou um programa com 100 estratégias escolhidas ao acaso, todas de Tit for Tat Generoso, em proporçốes variáveis (um perdão em cada cinco retaliaçóes, em cada três etc.). Neste torneio a estratégia dos traidores venceu. Adicionando-se, porém, uma pequena proporção do Tit for Tat (cerca de 1\%) o resultado muda. Ocorre que o Tit for Tat Generoso não tem a força suficiente para organizar a emergência da 
cooperação. É necessária uma dose pequena (a semelhança de uma força policial) do Tit for Tat para refrear os traidores. Todavia, no final, esta última estratégia não prevalece. Ela apenas propicia a sobrevivência e a dominação da estratégia Tit for Tat Generosa. Por 100 gerações os traidores empedernidos dominam a população que se torna extremamente feroz. Uma minoria assediada de Tit for Tat sobrevive a beira da extinção. Mas quando os tolos, ou apenas justos, são quase extintos e não,sobra ninguém para explorar, o jogo muda de direção. Os traidores começam a brigar entre si e se enfraquecem. Após 100 gerações a maioria muda dos traidores para os legais (Tit for Tat) e, após $\mathbf{3 0 0}$ geraçôes, dos legais para os muito legais (Tit for Tat Generoso).

É claro que estes modelos não conseguem representar a complexidade muito maior das situações humanas. Podem ser, no entanto, um interessante recurso heurístico para a compreensão de tais fenômenos.

Ainda mais, na vida real as ocorrências do dilema do prisioneiro não versam sobre díades isoladas. Em geral, o contexto social no qual ocorrem permite aos atores não só variarem o seu desempenho (cooperar ou trair), como escolherem os próprios parceiros. Até mesmo relações duráveis como o casamento e a amizade permitem a opção entre parceiros alternativos.

Para simular este fato Yamagishi, Hayashi \& Jin (7) apresentaram um projeto de pesquisa em que eram criadas situaçóes nas quais cada membro do grupo podia selecionar seu parceiro para o torneio. Isto significava que dois participantes formavam uma relação por mútua escolha e cada um deles era livre para abandonar a relação.

A partir deste esquema foi montado um torneio no qual foram diferenciados dois gêneros de estratégias.

Estratégia de ação: como decidir entre a cooperação $(\mathrm{X})$ e a traição $(\mathrm{Y})$.

Estratégia de seleção: como selecionar um parceiro.

Para este torneio, que foi denominado de rede do dilema do prisioneiro, foram convidados pesquisadores em dilemas sociais que deveriam apresentar softwares de estratégias a serem aplicadas.

Nestes experimentos estes pesquisadores propuseram nove estratégias que foram denominadas de Purge, Hifi, Oda, Nakayoshi, Ender, Suitor, Ansf Nepotism e Dken.

As características destas estratégias eram: 
- Estratégias de ação

$(\mathrm{TFT})=(\mathrm{T})=$ Tit-for-Tat: $\mathrm{o}$ jogador inicia com a estratégia de cooperação $X$; se $B$ também joga $X$, A repete $X$; se $B$ joga a deserção $\mathrm{Y}$, A também joga $\mathrm{Y}$.

$(\mathrm{UC})=(\mathrm{C})=$ Cooperação incondicional. A sempre joga $\mathrm{X}$, seja qual for a resposta de B.

(CD) = Cooperação incondicional com amigos e deserção sistemática com estranbos.

(TD) = TFT com amigos. Deserçáo incondicional com estranbos.

- Estratégias de seleção

Out-for-tat = Envolve tanto estratégia de ação como de seleção.

(OFT) Se o jogador B continua cooperando (estratégia X), A continua a escolher B como parceiro e coopera plenamente. Se falha em cooperar integralmente, A o abandona e escolhe outro parceiro.

(F) = Perdão para os inimigos.

(UF) = Não há perdão para os inimigos.

Método de alocaçáo de prioridade

= Alta prioridade para os "amigos"; prioridade para os "amigos” baseada na freqüência das relaçóes passadas.

$=$ Locação aleatória de prioridades.

Foram utilizadas as seguintes definiçóes:

estranhos : aqueles com os quais ainda não houve interação;

inimigos : aqueles que desertaram (jogaram $Y$ ) pelo menos uma vez numa interação passada;

amigos : aqueles que sempre cooperaram nas interações passadas.

O quadro a seguir mostra o resultado médio de cada estratégia na simulação em que foram utilizadas as nove estratégias mencionadas. O programa vencedor do torneio foi a estratégia Purge proposta por T. Kameda, da Universidade de Toyo. O segundo lugar coube à estratégia Hifi proposta por A. Diekmann, da Universidade de Berna, seguida de perto pela estratégia Oda proposta por $\mathrm{T}$. Oda, do Instituto de Pesquisa Social do Japão. 


\begin{tabular}{|c|c|c|c|c|c|c|}
\hline \multirow[t]{2}{*}{$\begin{array}{l}\text { Nome das } \\
\text { Estratégias }\end{array}$} & \multicolumn{4}{|c|}{$\begin{array}{l}\text { Características } \\
\text { das Estratégias }\end{array}$} & \multirow[t]{2}{*}{$\begin{array}{l}\text { Resultado } \\
\text { Médio }\end{array}$} & \multirow[t]{2}{*}{$\begin{array}{l}\text { Desvio } \\
\text { Padrão }\end{array}$} \\
\hline & 1 & 2 & 3 & 4 & & \\
\hline Purge & C & OFT & $\mathbf{F}$ & $\mathbf{R}$ & 496.7 & 11.0 \\
\hline Hifi & C & OFT & $\mathbf{U}$ & G & 490.6 & 28.2 \\
\hline Oda & C & OFT & $\mathbf{U}$ & $\mathbf{G}$ & 482.9 & 53.3 \\
\hline Nakayoshi & $\mathrm{T}$ & OFT & $\mathrm{F}$ & $\mathbf{G}$ & 478.0 & 74.9 \\
\hline Ender & $\mathbf{T}$ & não & $\mathbf{F}$ & outra & 477.8 & 44.1 \\
\hline Suitor & $\mathbf{T}$ & กล̃o & $\mathbf{F}$ & outra & 468.8 & 55.2 \\
\hline Ansf & $\mathrm{CD}$ & não & F & $\mathbf{G}$ & 450.4 & 82.3 \\
\hline Nepotism & $\mathrm{TD}$ & não & $\mathbf{F}$ & outra & 447.0 & 113.4 \\
\hline Ken & C & não & $\mathbf{U}$ & $\mathbf{R}$ & 204.1 & 188.2 \\
\hline
\end{tabular}

Este quadro é classificado de acordo com as quatro características mencionadas: (1) tipo de ação, (2) OFT ou não, (3) perdão aos inimigos ou não, (4) alocação de prioridades.

Em primeiro, lugar notamos que as quatro estratégias que utilizaram a característica OFT se saíram melhor do que as que não utilizaram tais estratégias. Além disso, as três primeiras colocadas - Purge, Hif e Oda - usaram a cooperação incondicional como estratégia de ação. Do exame do quadro se conclui que se a escolha do parceiro obedece ao critério do princípio do OFT, a estratégia de ação é redundante.

A principal conclusão dos resultados deste torneio é que a estratégia de seleção é mais importante do que a estratégia de ação.

Qual o interesse maior de experimentos que simulam de desempenhos correlatos às situaçóes semelhantes ao dilema do prisioneiro a ponto de atualmente existirem centros e simpósios internacionais destinados a explorar precisamente este setor? (8)

A questão subjacente, que torna interessante este tipo de pesquisa, é a ocorrência de inúmeras situações, na atualidade, nas quais torna-se relevante a possibilidade de se fazer emergir comportamentos de desapego a benefícios individuais imediatos em troca de benefícios coletivos futuros.

Transportar este problema da esfera das crenças religiosas ou da razão prática, registros que historicamente não se mostraram muito eficazes para melhorar o comportamento ético das pessoas, para a esfera das ciências do comportamento significa aumentar a compreensão das leis (9) ou constriçóes que governam o comportamento social. 
Muitos problemas, como proteção do meio ambiente, conservação dos recursos naturais, controle da natalidade entre outros - e particularmente entre nós, a questão premente da distribuição iníqua da renda nacional (10), demandam de imediato um esforço comum dos mais privilegiados $\mathrm{em}$ favor dos despossuídos, mas que no futuro poderá beneficiar a todos. $O$ desafio é induzir as pessoas a contribuirem para causas comuns quando as ações egoístas trazem maiores benefícios individuais e imediatos.

Em resumo, esses dilemas sociais envolvem grupos de pessoas tentando conseguir benefícios comuns na ausência de coerção externa, ou mesmo crenças introjetadas.

Cada indivíduo deve escolher entre contribuir para um bem comum ou ter um comportamento apenas egoísta e imediato. Cada um que coopera em certa medida deveria receber um benefício proporcional. Quando em grupo, o custo da cooperação excede seu quinhão de benefícios, as pessoas que dele fazem parte passam a ter um comportamento egoísta. Se o número de pessoas que coopera cai abaixo de determinado limiar, a expectativa do prejuízo exclui a cooperação e os indivíduos desertam desse comportamento.

A emergência de comportamentos coletivos cooperativos ou apenas egoístas parece ser função de determinadas massas críticas destes comportamentos dentro de uma determinada população (Glauce \& mHuberman, 1994: 58-63).)

O exposto nos leva a considerar relevantes as pesquisas, ou apenas reflexóes, que nos podem tornar um pouco mais imunes à infâmia da lei de Gerson.

Finalmente, se nos atrevêssemos a cometer a blasfêmia de tentar naturalizar os preceitos bíblicos mencionados na epígrafe, diríamos que, até o momento, os experimentos simulados do dilema do prisioneiro indicam que os desempenhos que melhor podem fazer emergir a cooperação como um comportamento estável, não correspondem aos ensinamentos do Velho Testamento e, tampouco, ao Novo, mas a algo que se situa entre os dois: $O$ Tit for Tat Generoso.

\section{Notas}

1 Em sua forma moderna, a interpretação darwiniana da evolução afirma que a evolução consiste em mudanças na frequiência do aparecimento de diferentes genes na população. A frequiência do aparecimento de um particular gene apenas pode aumentar se este gene aumenta a adaptaf̧āo danwiniana, que é proporcional ao número de descendentes possuidores deste gene e que sobrevivem. Ocorrem muitas instâncias do comportamento animal que parecem não contribuir para a sobrevivência do indivíduo que exibe este comportamento. É o caso do 
desempenho chamado de altruista.Um exemplo clássico é o da abelha operária que deixa o seu ferrão no intruso e, em consequiência, morre na defesa da colméia. O paradoxo é evidente: como pode um gene que se suicida se tornar estável: A preocupação com este e outros comportamentos análogos conduziu ao casamento entre duas disciplinas: a genética populacional e a etologia.

2 LORENZ, K. Studies in Animal and Human Behavior. Harvard, Univ. Press, 1971, p. 148: “... A pesquisa do comportamento comparativo conduz à inevitável conclusão que a estrutura do comportamento social humano incorpora uma série de funções, geralmente vistas como fenômenos racionais/responsáveis/éticos, mas que, em realidade, deveriam ser definitivamente classificadas como os padrões de comportamentos de animais que exibem apenas analogias funcionais com os processos éticos...”

3 J. B. S. Haldane. The Causes of Evolution, New York, Longmans and Green, 1932, p. 207 foi, talvez, o primeiro pesquisador a chamar a atenção para o problema que denominou de "características socialmente vantajosas, mas individualmente desvantajosas". Ele estava interessado na questão de saber como os "traços altruístas", que poderiam ser importantes para a humanidade, se reproduziam geneticamente em alguns animais. Haldane descobriu que, em grandes populações, as vantagens biológicas da conduta altruísta superam as desvantagens, apenas se uma parte substancial do grupo ou horda se comportar altruisticamente. Haldane introduziu o princípio da seleção familiar, através do qual os genes responsáveis pelo comportamento altruísta comparecem em grupos familiares e assim se perpetuam graças ao sacrifício do animal altruísta em favor da sua familia. O altruísmo familiar, como é chamado quando favorece clãs, não é, todavia, o único a ocorrer. Os morcegos vampiros da espécie Desmodus rotundus exibem um comportamento altruísta que não favorece familiares, mas indivíduos sem traços comuns de parentesco. (WILKINSON, G,.S. Food sharing in vampire bats. New York, Scientific American, p. 64-71, fev. 1990). O comportamento da divisão do alimento, ou outras formas de desempenho altruísta entre indivíduos sem traços de parentesco, tem sido também observado entre outros animais como chimpanzés selvagens, certas espécies de peixes etc.Cf. BASS, T. A. Forgiveness Math.Discovery, N.Y. Maio 1993, p. 62/67.

4 O Homem Econômico é um tipo ideal no sentido weberiano. Para os economistas clássicos denotava uma abstração que salientava no ser humano, o egocentrismo, a busca do prazer, a fuga do sacrifício e um cálculo racional neste tipo de agir, um cálculo hedonista para maximizar o prazer e minimizar a dor. Atualmente os economistas atribuem três atributos a este tipo ideal, conceito importante de sua ciência: Ser completamente informado. Ter sensibilidade contínua.Ser racional.

5 É impossível fornecer aqui um léxico completo dos termos empregados na teoria de jogos. Definiremos apenas os termos a medida de sua ocorrência. Assim, Estratégia dominante é aquela cujos resultados são melhores ou iguais aos das estratégias dominadas e pelo menos um resultado é melhor. Princípio Minimax é uma estratégia na qual o melhor dos piores resultados é o máximo que um jogador pode obter contra um oponente racional num jogo de soma-zero. Jogos de soma zero são aqueles de pura competição. Nestes jogos, o que um jogador ganha é exatamente o que o outro perde. Não há ganhos comuns nem colaboraçáa possível entre os jogadores.

6 O dilema do prisioneiro jogado em dois lances pressupõe um cálculo da combinação das estratégias do primeiro e segundo lance de ambos os participantes, sem que possa haver qualquer comunicação entre eles.

7 YAMAGISHI, T., HAYASHI, N. e JnN, N. (Hokkaido University), "Prisioner's Dilemma Network: Designation Strategy versus Action Strategy" Paper presented at the fifth International Conference on Social Dilemmas, Bielfeld, Germany, July 12-15, 1992. (Mimeo). 
8 NATO, Advanced Study Institute Cooperation: Game Theoretic Approaches, (Institute for Decision Sciences, SUNY, at Stony Brook, N.Y, 18 a 29 de Julho de 1994. Os tópicos deste simpósio se referem, em sua totalidade, à questão da cooperação.

9 Trata-se de "leis", não no sentido de constriçóes inalteráveis como são entendidas as leis das ciências naturais, mas coerções a que os atores, sujeitos-objetos destas "leis" podem alterar, numa certa medida e em determinadas circunstâncias. (EPSTEIN, I "Jogos". In Ciência e Filosofia, $\mathbf{n}^{\mathrm{o}} 1$ FFLCH-USP, 1979 , p. 85/98)

10 Demasiado presente uma vez que o Brasil é do mundo o país que apresenta o pior índice de distribuiçáo de renda. (World Development Report, 1993, World Bank, 1973, Oxford, Univ. Press, p. 238/192/296).

\section{Referências Bibliográficas}

ROUANET, S. P. Dilemas da moral iluminista. In: NOVAES, A. (org.), Ética. São Paulo, Cia. das Letras, 1992.

LORENS, K. Studies in animal and buman behavior-Harvard University press, 1971.

HALDANE, J.B.S. The causes of edolution.New York, Sngmans \& Green, 1932.

VON NEUMAN, G. \& MORGENSTEIN, O. Theory of games and economic behavior (cap. I). New York, G. Wiley \& sons Inc., 1967.

WILKINSON, G.S. Food sharing in vampire bats. New York, Scientific American. p. 64-71, fev. 1990.

BASS, T.A. Forgineness Math. New York, Dicovery, p. 62-67, maio 1993.

RAPAPORT, A. Strategy and conscience. New York, Schocken Books, 1969, p. 48-57.

AXELROD, R. The evolution of corporation. New York, Basic Books, 1984.

YAMAGISHI, T.; HAYASHI, N. \& JIN, N. Prisioner's dilemma network: designation strategy persus action strategy. V International Conference on Social Dilemmas. Bielfeld, Germany, July 1215,1992 [mimeo].

EPSTEIN, I. Jogos. In: Ciência e Filosofia, n.1, p. 85-98. Faculdade de filosofia, Letras e Ciências Humanas, USP, 1979.

GLANCE, N.S. \& HUBERMAN, B.A. The dynamics of social dilemmas. In: Scientific American, p. 58-63, mar. 1994.

\section{Resumo}

Historicamente os termos altruismo e ética têm ocorrido mais freqüentemente nos discursos religiosos ou filosóficos do que nos textos sobre ciências do comportamento. Recentemente, uma situação de interação humana denominada de dilema do prisioneiro tem servido de palco para torneios entre programas de computador que simulam os parâmetros desta situação. Os resultados mostram que os programas baseados em estratégias cooperativas atribuem a seus praticantes maior capacidade de sobrevivência do que os programas baseados em estratégias apenas predatórias ou competitivas. 


\begin{abstract}
Historically the words altruism and ethics ocurre rather in religious or philosophical discourses than in texts about behavioral sciences. Recently, however, a theoretical approach of one kind of human interaction called Prisioner's Dilemma generated softwares designed by researchers in the field that simulate this situation. The results of computer tournamentes among different designs of softwares reveals that those strategies based in cooperation gave to their performers a better chance of survival then the softwares based on predatory or competitive strategies.
\end{abstract}

Isaac Epstein é professor no centro de pós-graduação em Comunicação Social da Universidade Metodista de São Paulo e autor de Gramática do Poder (Ática, 1994) e Revoluçôes Cientificas (Ática, 1988), entre outros livros.

Trabalho apresentado em congresso organizado pelo Centro de Inovação e Cooperação Tecnológica da Universidade de Amsterdã (Holanda), de 17 a 21 de abril de 1995. 